\title{
THE EFFECT OF MOTIVATIONAL INSTRUCTIONS ON P300
} AMPLITUDE

\author{
Authors: M.T. Carrillo-de-la-Peña, F. Cadaveira
}

This is the peer reviewed version of the following article: Carrillo-de-la-Peña M.T.; Cadaveira, F. (2000). The effect of motivational instructions on P300 amplitude. Neurophysiologie Clinique / Clinical Neurophysiology, 30, 232-239. doi: 10.1016/s0987-7053(00)00220-3

This article may be used for non-commercial purposes in accordance with Elsevier Masson, Elsevier and Société de Neurophysiologie Clinique de Langue Française terms and conditions for use of self-archived versions. 


\title{
The effect of motivational instructions on P300 amplitude
}

\author{
Authors: M.T. Carrillo-de-la-Peña, F. Cadaveira
}

Department of Clinical Psychology and Psychobiology, University of Santiago de Compostela, 15705 Santiago de Compostela, Spain 
Summary - The aim of this investigation was to determine the effect on P300 amplitude of instructions aimed at increasing the subject's degree of task involvement. To this end, two different studies were carried out. In Study 1, 20 university students were tested with an auditory event-related potential (ERP) oddball paradigm (target: $1100 \mathrm{~Hz}$; standard: $1000 \mathrm{~Hz}$ ) in two consecutive runs, each with a different set of instructions; after the first run, subjects wereverbally motivated to increase their level of performance in the second run. In Study 2 (performed 1 year later), ERPs were similarly obtained from the same subjects during two oddball runs, but this time both tests were preceded by neutral instructions. The amplitude and latency of N1 and P2 elicited by non-targets and of N2 and P3 in target waveforms were evaluated. The findings showed that following motivating instructions, P3 amplitude increased whileP3 latency showed a nonsignificant decrease. The amplitude of P2 to non-target stimuli - which could be interpreted as P250 - was also affected by the instructions provided. The overall results suggest that the presentation of motivating instructions is followed by a higher amount of attentional resources allocated to all stimuli, and a more efficient evaluation and discrimination of relevant targets. The implication of these findings for the clinical use of P300 has been discussed. (C) 2000 Éditions scientifiques et médicales Elsevier SAS

\section{P300 / ERP / motivation / clinical application / task involvement}

Résumé - Effet des instructions motivantes sur l'amplitude du P300. L'objectif de ce travail était d'étudier l'effet sur l'amplitude du P300 des instructions données aux sujets pour augmenter leur motivation lors de la réalisation d'un paradigme oddball. Pour cela, nous avons réalisé deux études différentes. Dans l'étude 1, une tâche oddball auditive (cible : $1100 \mathrm{~Hz}$; fréquence : 1000 $\mathrm{Hz}$ ) a été présentée à 20 étudiants ; après une première série standard, les sujets ont reçu des instructions visant à augmenter leur degré de motivation dans la deuxième série. Dans l'étude 2, réalisée un an plus tard, les performances des mêmes sujets ont été enregistrées pendant la réalisation de deux séries oddball, toutes les deux précedées d'instructions standards. L'amplitude et la latence du N1 et du P2 obtenues en réponse aux sons fréquents et l'amplitude et la latence du N2 et du P3 aux stimuli cibles ont été étudiées. Dans la série précédée des instructions motivantes, l'amplitude du P3 était augmentée ; sa latence était raccourcie mais de façon non significative. L'amplitude du P2 aux fréquences - aussi interpreté comme le P250 - était également modifiée par les instructions. Les résultats de cette étude suggèrent que la présentation d'instructions motivantes entraine une évaluation et une discrimination des stimuli significatifs plus efficace ; celai semblant reflèter une plus grande quantité de resources attentionnelles allouées à tous les stimuli. Les implications de ces résultats pour l'application clinique du $\mathrm{P} 3$ sont discutées. (C) 2000 Éditions scientifiques et médicales Elsevier SAS

\section{P300 / ERP / motivation / application clinique}

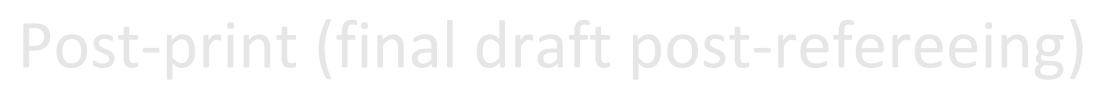


The P300 component of event-related potentials (ERPs) has been extensively investigated in clinical practice as it provides an easily obtained, noninvasive index of general cognitive functioning. Longer P3 latencies, related to an increased delay in stimulus classification in a discrimination task, have been found in elderly subjects [16, 24], and in patients with dementia $[1,10]$, early Alzheimer's disease [26] or in cases of alcoholism [4, 42], among others. A decrease in P3 amplitude has also been clinically observed in depressive [3], schizophrenic [13] and alcoholic subjects [28], and has been identified as a risk marker for alcoholism or the development of a psychopathology $[27,30,32,33,35]$.

The clinical use of P3 has been based on a large number of studies on the basic parameters that influence its amplitude and latency [20]. Johnson systematized this field of research and proposed a 3-component model, namely, subjective probability, stimulus meaning, and transmission of information [14]. Nevertheless, research has been mainly focused on task-related variables, and very few studies have investigated the effect of other non-specific factors present at the time of recording that may have a decisive influence on P3 indices. For instance, Johnson [14] stated that the 'stimulus meaning' dimension is defined by task complexity, stimulus complexity and stimulus value, and that this latter variable is mainly determined by the amount of reward associated with the discrimination of stimuli. Nevertheless, in his model little attention was given to the subject's positive disposition or motivation to efficiently perform a discrimination task such as the oddball paradigm, a variable which may determine the subjective meaning of the task. This task-involvement factor may be crucial in a clinical setting, taking into account the fact that patients are quite often unwilling to participate in the recording process or find it difficult to perform the required tasks. The relevance of task involvement in specific settings has been illustrated by Laurent et al. [17], who pointed out that one of the methodological difficulties in studying the P300 component in schizophrenic patients was to obtain adequate patient-control matching for motivation. In fact, 'motivation' has often been used as an explanatory factor for variations in P300 parameters in schizophrenic [19, 36, 40] and depressive patients [5], subjects with migraine [7], or the elderly [41]. Polich and Kok have also suggested that other non-specific factors such as arousal may affect P3 amplitude [25]

Although several studies have indicated that the reduction in P300 amplitude in some clinical groups may be due to a motivational deficit, the effect of motivation on the P3 component has not been systematically addressed in the literature. The existing research has focused on the incentive value of the stimuli, which seems to affect P3 amplitude but not its latency. Larger amplitudes have been found when the monetary value of the target is increased $[2,12]$ or when it is used as a feedback stimulus (i.e. when it signifies a correct performance, rather than when it is simply counted) [14]. The effect of an incentive on P3 amplitude has also been examined in clinical and control groups. It has been found that alcoholics or subjects with a family history of alcoholism did not show larger P300 amplitudes to the target whether it implied reward or loss of reward [29, $31]$.

Given the potential relevance of motivation on ERP parameters, in the present study we attempted to analyze the effect of this variable using a different strategy. The aim was to determine to what extent the subject's degree of task involvement, influenced by the instructions provided, might affect the P3 component. To this end, the ERPs were recorded in two consecutive series while subjects performed an oddball task consisting of discrimination between $1000 \mathrm{~Hz}$ (standard




stimulus) and $1100 \mathrm{~Hz}$ (target stimulus) tones. The first run in Study 1 was preceded by neutral instructions, and the second by instructions aimed at motivating the subjects and increasing their level of proficiency in the performance of the task. To take into account the possible effects of practice or habituation on the $\mathrm{P} 3$, in two repeated occasions, in a similar study the same subjects performed two consecutive oddball tasks but only received neutral instructions, and not motivating instructions before the second run (Study 2). This work is part of a longitudinal research project aimed at standardizing the recording protocols for university students, and in this context the recordings for Study 1 and Study 2 were therefore separated by an extended period (1 year). It was expected that the presence of motivating instructions (Study 1, second run) would increase the amount of attentional resources allocated to the task, and consequently produce an enhancement of P300 amplitude.

\section{Materials and methods}

\section{Subjects}

Twenty university students ( 8 males, 12 females) aged between 18-23 years (mean age: 19 years, SD: 1.37 years) contacted over two consecutive years were included in the study. All subjects were in good health and had no history of neurological or psychiatric disorder, or drug abuse. Stimuli and procedure Subjects were exposed to pure-tone beeps of $50 \mathrm{~ms}$ duration $(10 \mathrm{~ms}$ rise and fall) and $60 \mathrm{~dB}$ SPL by means of earphones. The interstimulus interval (ISI) was $1500 \pm 100$ $\mathrm{ms}$, and the interval between runs was approximately $2 \mathrm{~min}$. Subjects had to detect the targets (1 $100 \mathrm{~Hz}$ ) inserted randomly between standard $(1000 \mathrm{~Hz})$ tones, and press a button with the dominant hand when the targets appeared. Each run consisted of a sequence of 200 stimuli, with a global probability for targets of 0.20. In Study 1, subjects performed two consecutive oddball tasks with different instructions for each. The first series was preceded by the following instructions: "Now you will hear two types of tone; some of them are high-pitched ('bip') while the others, which are more frequent, are low-pitched ('bop'). Whenever you hear a 'bip' you must press this button as fast as possible. Please try to avoid unecessary movements or blinking during the test". After a 2-minute rest period, a second series was presented with the following instructions: "Now you have to accomplish the same task as before,but this time it is particularly important that you do well. We are recording your performance on the computer, and your data will be compared with the classroom standards. Remember that it is important to avoid unecessary movements or blinking during the test". Study 2 was carried out 1 year later. Subjects again performed two consecutive oddball tasks, but this time both were preceded by the same neutral instructions as in the first run of Study 1.

\section{ERP recordings}

For this investigation, EEG activity was recorded with tin electrodes at $\mathrm{Fz}, \mathrm{Cz}$ and $\mathrm{Pz}$ electrode sites, referenced to the nose. An electrode placed on the forehead served as ground. Additional electrodes placed above and below the left eye were used to monitor ocular artifacts.

EEG activity was filtered with a bandpass of $0.1-30 \mathrm{~Hz}$ ( $24 \mathrm{~dB} /$ octave rolloff) and amplified 20 $\mathrm{k}$. Electrode/skin impedance was kept below $5 \mathrm{k} \Omega$. Signals were sampled continuously at a rate of $500 \mathrm{~Hz}$. The signal was processed off-line: first the EEG was corrected for vertical ocular movements, using the algorithm developed by Semlitsch et al. [34], and then the EEG was epoched from $100 \mathrm{~ms}$ pre-stimulus to $900 \mathrm{~ms}$ post-stimulus. Linear trends were eliminated, the signal was adjusted to $0 \mu \mathrm{V}$ pre-stimulus baseline and filtered with a digital filter $(0.1-30 \mathrm{~Hz})$.




Trials affected by electromyographic activity or other artifacts $( \pm 90 \mu \mathrm{V})$ were identified by visual inspection and then rejected.

\section{Data analysis}

In each study, average ERPs were computed separately at $\mathrm{Fz}, \mathrm{Cz}$ and $\mathrm{Pz}$ for each run (1st/2nd) and stimulus category (target/non-target). The averaged ERPs were analyzed with a semiautomatic peak detection program, using a computer algorithm which searched for the maximum/minimum peak amplitude within predefined latency windows. Peaks were then verified and adjusted by visual inspection. Amplitude and latency values were automatically transferred to an ASCII file for subsequent analysis.

The peaks identified were N1 (75-150 ms) and P2 (150-250 ms) for the waveforms elicited by standards, and N2 (200-300 ms) and P3 (275-450 ms) for those elicited by targets.

Data were analyzed with a repeated measures analysis of variance (ANOVA) using study (1st versus $2^{\text {nd }}$ year), run ( 2 runs) and electrode sites ( 3 sites) as with in subject factors. Separate analyses were carried out for each component latency and amplitude. Significant levels were determined using degrees of freedom adjusted by the Greenhouse-Geisser correction when divergence from the assumption of sphericity was found to be significant [39]. Significant effects were examined with paired $t$-tests.

\section{Results}

The overall averages of ERPs at $\mathrm{Fz}, \mathrm{Cz}$ and Pz obtained from non-target and target stimuli in the first and second studies have been shown in figures 1 and 2, respectively. The waveforms recorded in the first and second runs are superimposed. Visual inspection of the waves shows an increase in P3 amplitude to targets in the second run, but only in Study 1. As can be seen in figure 2, the waveforms obtained in the first and second runs of Study 2 presented a marked degree of overlap.

Repeated measures ANOVA showed a significant study $\times$ run interaction on P3 amplitude to targets $(\mathrm{F}[1,19]=4.74 ; \mathrm{P}=0.04)$. This effect was independent of electrode positioning. As can be seen in table I, the presentation of motivating instructions in the second run of Study 1 provoked higher amplitudes at all the electrode sites. This P300 increase in the second run was not observed in Study 2 (table II).

For P2 amplitude to frequent stimuli, significant main effects were found for study $(\mathrm{F}[1,18]=$ $5.18 ; \mathrm{P}=0.035)$ and run $(\mathrm{F}[1,18]=4.55 ; \mathrm{P}=0.047)$, as well as a very significant study $\times$ run $\times$ electrode interaction $(\mathrm{F}[2,36]=6.96 ; \mathrm{P}=0.006 ; \varepsilon=0.78)$. A paired t-test revealed higher $\mathrm{P} 2$ amplitudes in the second run, but only in Study 1 and for $\mathrm{Cz}$ and $\mathrm{Pz}$.

Regarding latency values, significantly shorter N2 latencies were found in the second run in both studies $(F[1,16]=5.61 ; P=0.029$ for the run effect $)$. For $\mathrm{P} 3$ latency, there was a non-significant trend toward shorter latencies in the second motivated run of Study 1 for $\mathrm{Fz}$ and $\mathrm{Cz}(F[2,38]=$ $3.20 ; P=0.067 ; \varepsilon=0.78$ for the study $\times$ run $\times$ electrode interaction). No other effect or interaction was found to be significant for other latency or amplitude parameters.

To further clarify the effect of motivating instructions found in Study 1, the behavioral responses to targets in the first and second runs were additionally analyzed. In the first series, the mean running time (RT) was $457.99 \mathrm{~ms}$ (mean $\mathrm{SD}=104.73 \mathrm{~ms}$ ) with a $90 \%$ correct score, and in the 
second series the mean RT was $406.80 \mathrm{~ms}$ (mean $\mathrm{SD}=93.22 \mathrm{~ms}$ ) with a $93.88 \%$ correct score. Paired $t$-tests revealed a significant difference between both runs in the mean RT (two-tailed $t$ test, $t=2.92 ; P=0.009$ ).

\section{Discussion}

The results obtained here show that the ERP P3 component is affected by non-specific factors such as the motivation to perform a task correctly. Providing instructions aimed at increasing the subject's degree of involvement in the task seemed to result in a more efficient process of evaluation and decision-making regarding relevant stimuli, manifested both at the neurophysiological and behavioral level. An increase in P3 amplitude and a trend towards a decrease in P3 latency took place when an oddball task was preceded by motivating instructions.

The possibility of the increase in P3 amplitude in the motivated series being due to the facilitating effect of repetition was ruled out by Study 2 .

When both discrimination tasks were preceded by the same neutral instructions, no significant effects for run emerged. Under the motivated condition, however, the subject's behavioral performance was also significantly improved: although the responses were similarly accurate, the RT became significantly reduced when subjects were motivated.

A possible explanation for this study group's more efficient stimulus evaluation and discrimination under motivated conditions may be that, with a higher degree of task-involvement, subjects were more able to concentrate on target stimuli and to block out the irrelevant information from non-targets. However, this hypothesis is contradicted by the higher P2 amplitudes to nontarget stimuli, which were also found in the motivated series. P2 amplitude to frequent stimuli (also called 'P250' by some authors [9]) has been considered an index of the amount of central processing of non relevant stimuli during discrimination tasks $[6,9]$.

Thus, a hypothesis which is more consistent with our data could be that the efficiency in processing was determined by a higher degree of attentional resources allocated to all stimuli, even to non-targets, when subjects had been provided with motivating instructions.

This increase in processing ability may have been related to an increase in the level of general arousal or awareness induced by the instructions. This interpretation is, however, questioned by the fact that N1 amplitude, which one would expect to vary with different degrees of awareness [38], did not differ between study conditions. Nevertheless, as P3 amplitude is sensitive to changes in arousal [25], the possibility that the motivating instructions produced increasing arousal, which in turn increased the $\mathrm{P} 3$ amplitude, cannot be completely ruled out.

Motivating instructions produced a shortening of RTs without a significant change in P3 latency. This dissociation between P3 latency and RTs, also previously reported in the literature [18], may be understood by taking into account the nature of the task and the instructions provided. Since subjects were already very accurate in the first series ( $90 \%$ correct score), it is possible that the motivating instructions privileged a speed strategy in the second series. Consequently, and given the fact that the task requirement was exactly the same in both series, the instructions probably induced quicker responses without significantly changing the stimulus evaluation time. Pfefferbaum et al. also found that speed instructions had a stronger effect on RTs than on P3 latency [23]. The increased arousal due to receiving motivating instructions may also contribute 
to explaining the increase in response speed. As Hackley and Valle-Inclán have demonstrated, transient changes in arousal produced by a non-relevant accessory tone reduced the RTs [11].

Thus, instructions aimed at effectively motivating the subject produced an increase in P3 amplitude, which may be interpreted in the light of the triarchic model proposed by Johnson [14]. Motivation or task involvement is a non-specific factor that may increase stimulus value, one of the factors in Johnson's equation. It seems as if all the stimuli become more relevant when subjects are motivated in spite of that task difficulty, and stimulus probability keep constant. At a physiological level, the changes in ERPs induced by motivating instructions may be interpreted as the result of an increase in the activity of the noradrenergic system. Pineda et al. have demonstrated the role of this system on the generation and modulation of P3 amplitude in monkeys, and found a significant reduction in P3 amplitude after the administration of adrenergic alpha antagonists, or that had been caused by lesions of the locus coeruleus and its ascending fibers [21, 22]. Thus, it appears that the increase in the amount of attentional resources allocated to a task in motivated conditions could be associated with an increase in the activity of the noradrenergic system, and consequently, with an increase in P3 amplitude.

The above results may have some relevance for the interpretation of P3 amplitude as a clinical index, at least at group level. It is possible that the reduction of P3 amplitude in patient groups may be due to a motivational deficit. This motivational deficit has been found in alcoholics, whose P3 amplitudes do not seem to respond to the presentation of rewards associated with the discrimination task [29]. It has also been found that feedback training regarding a task produced an enhancement of P3 amplitude in schizophrenics, especially in those which presented a more defined reduction in P3 amplitude [8]. Also, P300 amplitude has been negative and significantly related to a state of despair and suicidal risk in a sample of depressive patients [37]. Nevertheless, the contribution of motivation to differences in P300 between patients and controls is not clear. Kemner et al. [15] did not agree with the view that P300 abnormalities in hyperactive children with attention deficit were secondary to an impairment in motivation. They found that these children presented significant reductions in P3 amplitude to diverse stimuli, irrespective of task relevance.

In summary, this study underlines the importance of motivation or task involvement in determining P3 amplitude and its interpretation for clinical purposes. 'Dynamogenic' factors such as motivation or emotion should be fully investigated in order to determine there al nature of the reduction in $\mathrm{P} 3$ amplitude in a number of psychopathologies. The present work provides a simple experimental assessment of task involvement which produces a significant increase in P3 amplitude, which could be easily adopted in specific settings. Nevertheless, it could be argued that the instructions provided in the present study may have had other consequences, such as raising the level of anxiety, which in turn may have influenced $\mathrm{P} 3$ parameters. Thus it is advisable that future studies include other kinds of reward (i.e., monetary) to test whether the P3 component in different clinical groups is sensitive to the manipulation of motivational levels.






\section{References}

1. Attias J, Huberman M, Cott E, Pratt H. Improved detection of auditory abnormality in dementia using a variety of stimuli. Acta Neurol Scand 1995 ; 92 : 96-101.

2. Begleiter H, Porjesz B, Chou CL, Aunon JI. P3 and stimulus incentive value. Psychophysiology $1983 ; 20: 95-101$.

3. Bruder GE, Tenke CE, Stewart JW, Towey JP, Leite P, Voglmaier M, et al. Brain eventrelated potentials to complex tones in depressed patients: Relations to perceptual asymmetry and clinical features. Psychophysiology $1995 ; 32: 373-81$.

4. Cadaveira F, Grau M, Roso M, Sanchey-Turet M. Multimodality exploration of eventrelated potentials in chronic alcoholics. Alcohol Clin Exp Res 1991 ; 15 : 607-11.

5. Diner BC, Holcomb PJ, Dykman RA. P300 in major depressive disorder. Psychiatry Res 1985: $15: 175-84$.

6. Donald MW. The timing and polarity of different attentionrelated ERP changes inside and outside the attentional focus. In: Johnson R, Rohrbaugh JW, Parasuraman R, eds. Current Trends in Event-Related Potential Research. Amsterdam: Elsevier; 1987. p. 816.

7. Drake ME, Pakalnis A, Padamadan H. Long-latency auditory event related potentials in migraine. Headache $1989 ; 29: 239-41$.

8. Fukuda M, Niwa S, Hiramatsu K, Hata A, Saitoh O, Hayashida S, et al. Behavioral and P3 amplitude enhancement in schizophrenia following feedback training. Schizophrenia Res $1997 ; 25: 231-42$.

9. García-Larrea L, Lukaszewicz AC,Mauguière F. Revisiting the oddball paradigm. Nontarget versus neutral stimuli and theevaluation of ERP attentional effects. Neuropsychologia $1992 ; 30: 723-41$.

10. Goodin DS, Aminoff MJ. Evaluation of dementia by eventrelated potentials. J Clin Neurophysiol $1992 ; 9: 521-5$.

11. Hackley SA, Valle-Inclán F. Automatic alerting does not speed late motoric processes in a reaction-time task. Nature $1998 ; 391$ : 786-8.

12. Hömberg V, Grünewald G, Grünewald-Zuberbier E. The variation of $\mathrm{P} 300$ amplitude in a money-winning paradigm in children. Psychophysiology $1981 ; 18: 258-62$.

13. Javitt DC, Doneshka P, Grochowski S, Ritter W. Impaired mismatch negativity generation reflects widespread dysfunction of working memory in schizophrenia. Arch Gen Psychiatry $1995 ; 52: 550-8$.

14. Johnson R. A triarchic model of P300 amplitude. Psychophysiology $1986 ; 23: 367-84$.

15. Kemner C, Verbaten MN, Koelega HS, Buitelaar JK, Van der Gaag RJ, Camfferman G, et al. Event-related brain potentials in children with attention-deficit and hyperactivity disorder: effects of stimulus deviancy and task relevance in the visual and auditory modality. Biol Psychiatry $1996 ; 40: 522-34$.

16. Kügler CFA, Taghavy A, Platt D. The event-related P300 potential analysis of cognitive human brain aging: a review. Gerontology $1993 ; 39: 280-303$.

17. Laurent A, García-Larrea L, Dalery J, Terra JL, Marie-Cardine M, Mauguière F. Etude du P300 dans la schizophrénie. Quelques réflexions sur les difficultés méthodologiques. Encéphale $1992 ; 18: 241-5$. 
18. Looren de Jong H, Kok A, Van Rooy J. Stimulus probability and motor response in young and old adults: an ERP study. Biol Psychol 1989 ; 29 : 125-48.

19. Louza MR,Maurer K, Neuhauser B. Changes in P300 latency and amplitude in schizophrenic patients and healthy controls during the examination. Electromyogr Clin Neurophysiol $1992 ; 32: 603-10$.

20. Picton TW. The P300 wave of the human event-related potential. J Clin Neurophysiol $1992 ; 9: 456-79$.

21. Pineda JA, Foote SL, Neville HJ. Effects of locus coeruleus lesions on auditory, longlatency, event-related potentials in monkey. J Neurosci $1989 ; 9: 81-93$.

22. Pineda JA, Westerfield M. Monkey P3 in an 'oddball' paradigm: pharmacological support for multiple neural sources. Brain Res Bull 1993 ; 31 : 689-96.

23. Pfefferbaum A, Ford J, Johnson R, Wenegrat B, Kopell BS. Manipulation of P3 latency: speed vs. accuracy instructions. Electroencephalogr Clin Neurophysiol $1983 ; 55$ : 18897.

24. Polich J. Meta-analysis of P300 normative aging studies. Psychophysiology 1996 ; 33 : 334-53.

25. Polich J, Kok A. Cognitive and biological determinants of P300: an integrative review. Biol Psychol $1995 ; 41$ : 103-46.

26. Polich J, Ladish C, Bloom FE. P300 assessment of early Alzheimer's disease. Electroencephalogr Clin Neurophysiol $1990 ; 77$ : 179-89.

27. Polich J, Pollock VE, Bloom FE. Meta-analysis of P300 amplitude from males at risk for alcoholism. Psychol Bull $1994 ; 115: 55-73$.

28. Porjesz B, Begleiter H. Effects of alcohol on electrophysiological activity of the brain. In: Begleiter H, Kissin B, eds. Alcohol and Alcoholism, Vol. 2. The Pharmacology of Alcohol and Alcohol Dependence. New York: Oxford Univ Press; 1996. p. 207-47.

29. Porjesz B, Begleiter H, Bihari B, Kissin B. Event-related brain potentials to high incentive stimuli in abstinent alcoholics. Alcohol 1987 ; 4 : 283-7.

30. Ramachandran G, Porjesz B, Begleiter H, Litke A. A simple auditory oddball task in young adult males at high risk for alcoholism. Alcohol Clin Exp Res 1996 ; 20 : 9-15.

31. Ramsey SE, Finn PE. P300 from men with a family history of alcoholism under different incentive conditions. J Stud Alcohol 1997 ; 58 : 606-16.

32. Schreiber H, Stolz-Born G, Kornhuber HH, Born J. Eventrelated potential correlates of impaired selective attention in children at high risk for schizophrenia. Biol Psychiatry $1992 ; 32$ : 634-51.

33. Schreiber H, Stolz-Born G, Rothmeier J, Kornhuber A, Kornhuber HH, Born J. Endogenous event-related brain potentials and psychometric performance in children at risk for schizophrenia. Biol Psychiatry $1991 ; 30: 177-89$.

34. Semlitsch HV, Anderer P, Schuster P, Presslich O. A solution for reliable and valid reduction of ocular artifacts applied to the P300 ERP. Psychophysiology $1986 ; 23$ : 695703.

35. Sharma A,Malhotra S, Raghunathan M, Malhotra A. A study of event-related potential P3 characteristics in children of alcoholics. Addict Biol 1997 ; 2 : 431-8.

36. Simons RF, Russo KR. Event-related potentials and continuous performance in subjects with physical anhedonia or perceptual aberrations. J Psychophysiol $1987 ; 1$ : 401-10. 
37. Urcelay-Zaldua I, Hansenne M, Ansseau M. Influence du risque suicidaire et du désespoir sur l'amplitude de l'onde P300 dans la dépression majeure. Neurophysiol Clin $1995 ; 25$ : 291-6.

38. Van Sweden B, Van Dijk JG, Caekebeke JF. Auditory information processing in sleep: late cortical potentials in an oddball paradigm. Neuropsychobiology $1994 ; 29$ : 152-6.

39. Vasey MW, Thayer JF. The continuing problem of false positives in repeated measures ANOVA in psychophysiology: a multivariate solution. Psychophysiology 1987 ; 24 : 479-86.

40. Verleger R, Bode M, Arolt V, Wascher E, Kömpf D. Differences in P3 amplitudes between schizophrenics and healthy controls vary between the different events presented in a guessing task. Neuropsychobiology $1994 ; 30: 114-23$.

41. Verleger R, Neukäter W, Kömpf D, Vieregge P. On the reasons for the delay of P300 latency in healthy elderly subjects. Electroencephalogr Clin Neurophysiol $1991 ; 79$ : 488- 502.

42. Wipple SC, Berman SM, Noble EP. Event-related potentials in alcoholic fathers and their sons. Alcohol $1991 ; 8: 321-7$. 


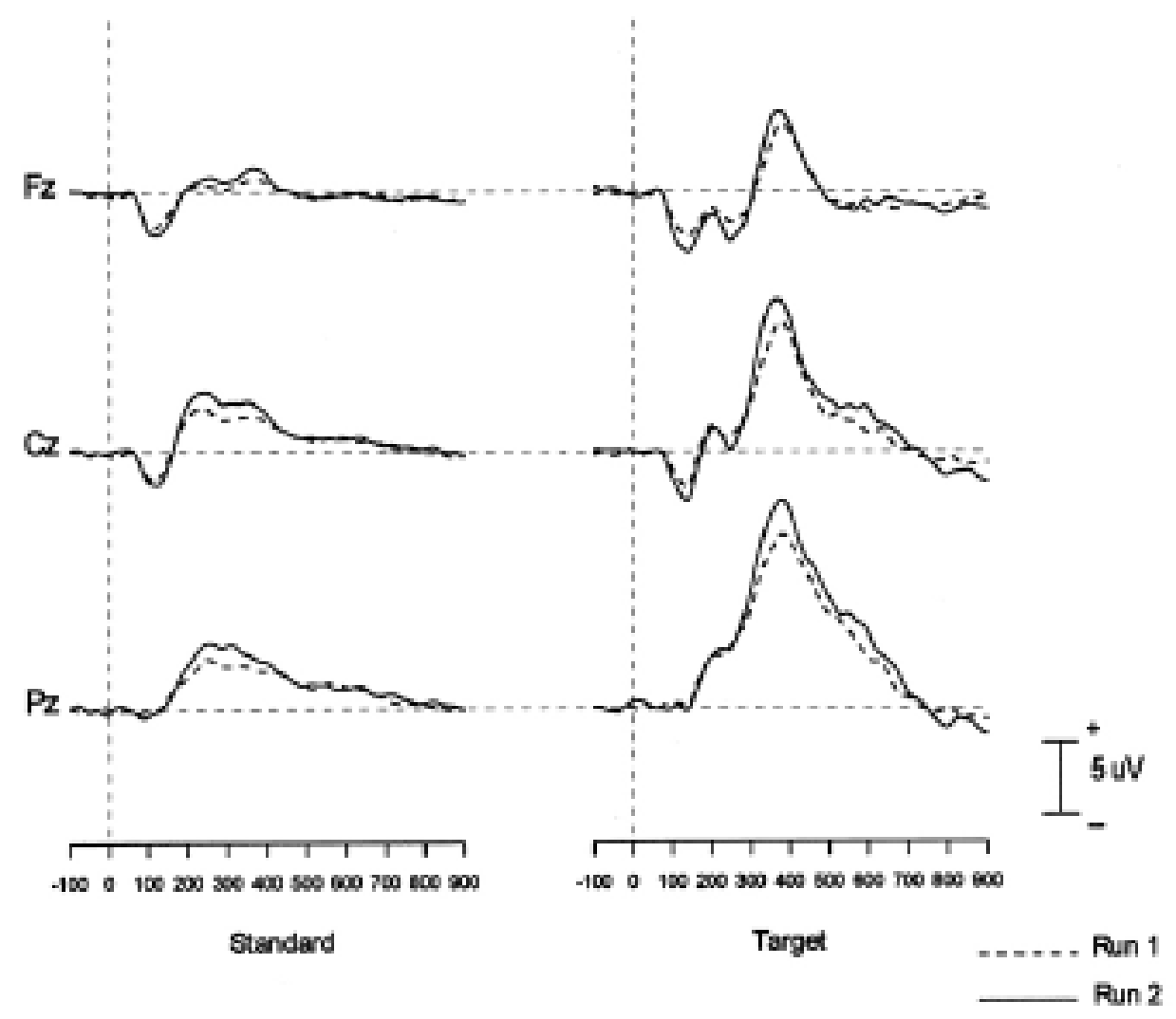

Figure 1. Overal means for audtory ERPs to standard and targat stimuli for the first and second runs in Study 1. 
Table L. Mean (SD) amplitude and latency values for N1 and P2 to standard stimuli, and for N2 and P3 to targets in first and second I Study 1.

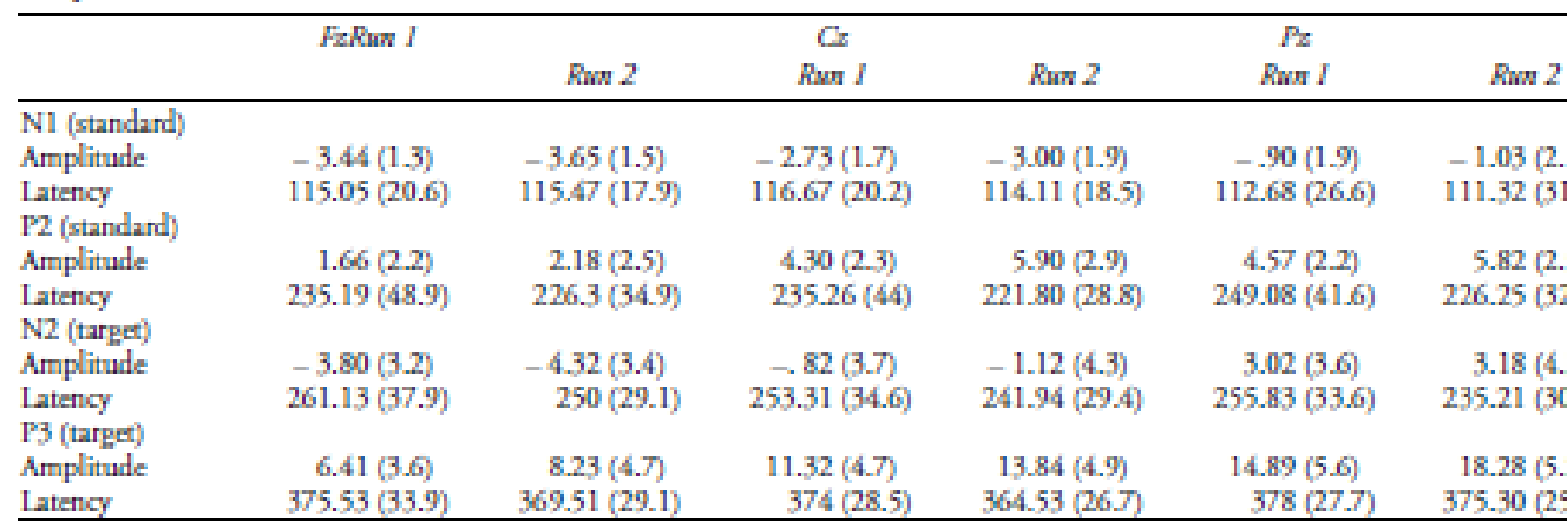

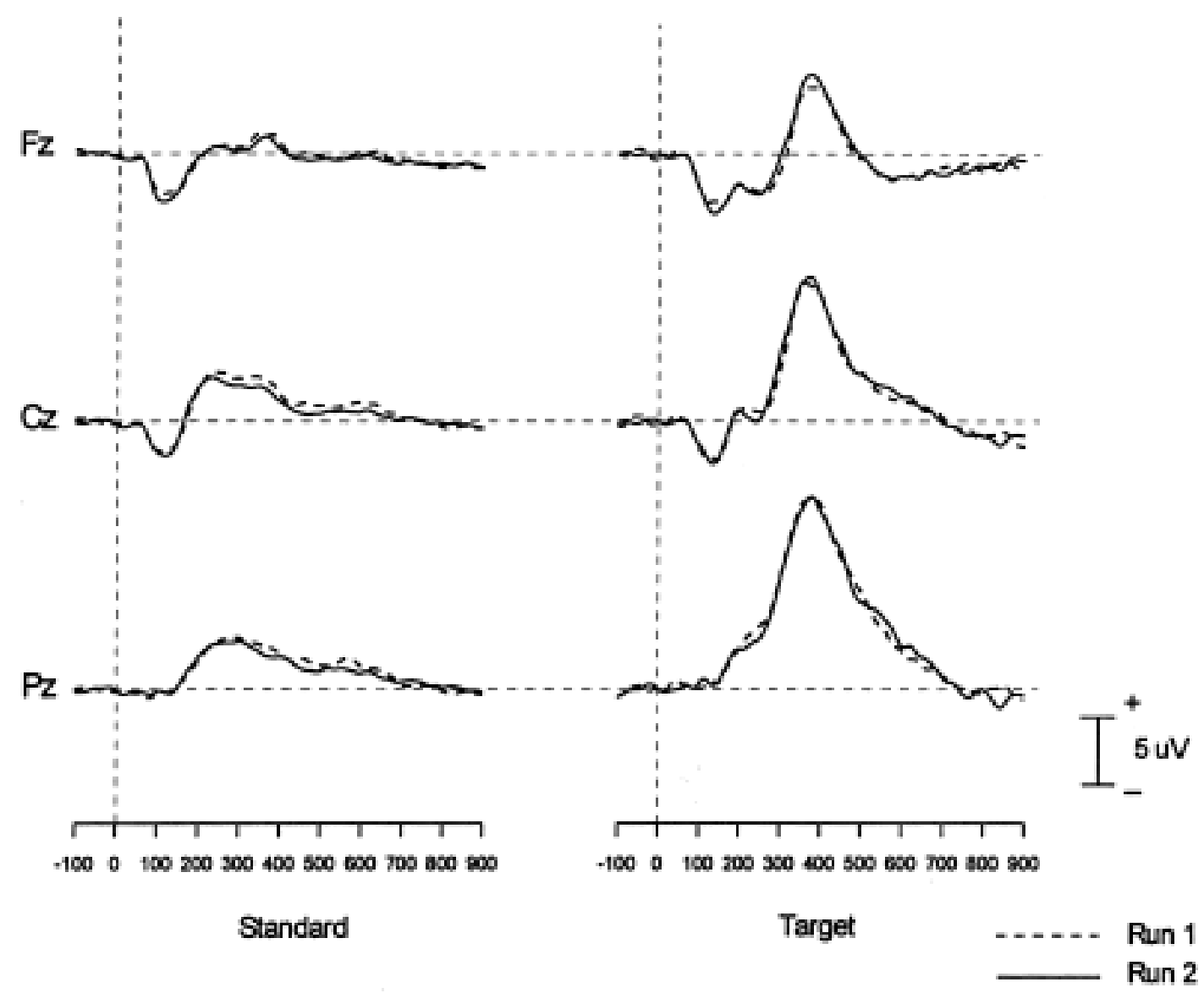

Figure 2. Overal means for audtory ERPs to standard and target stimuli for the first and second runs in Study 2. 


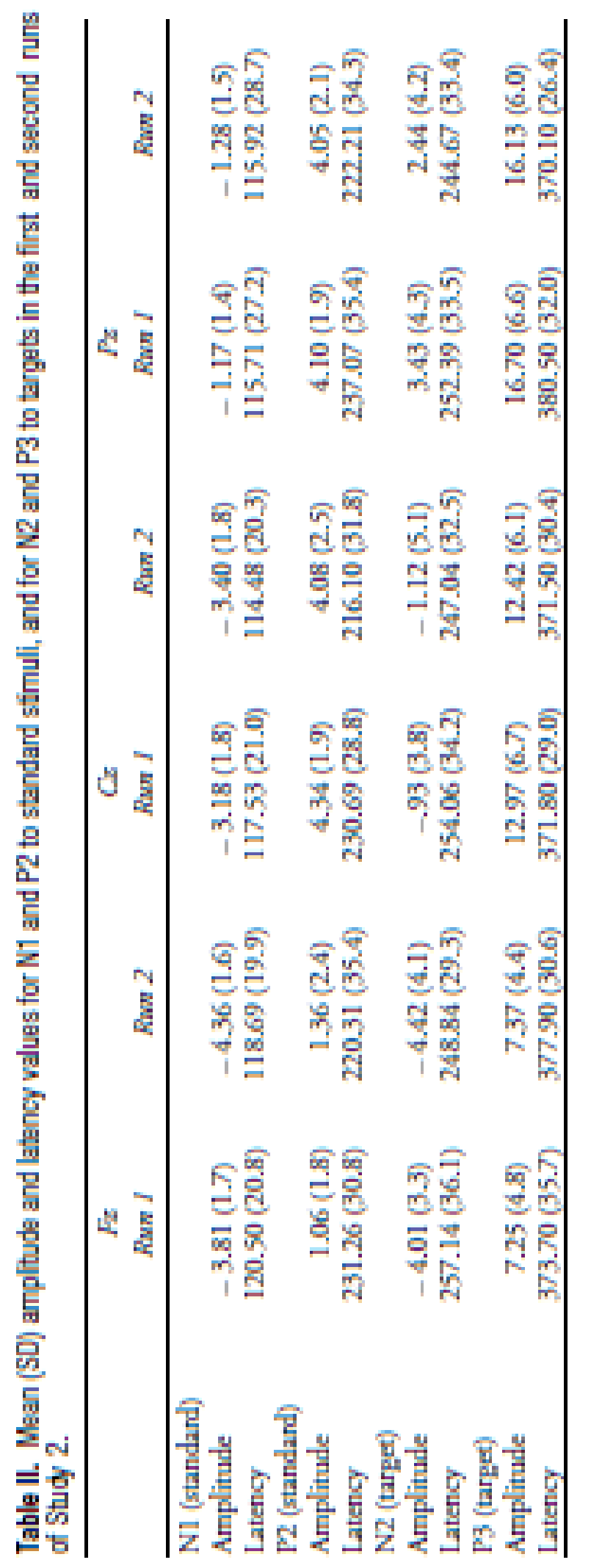

